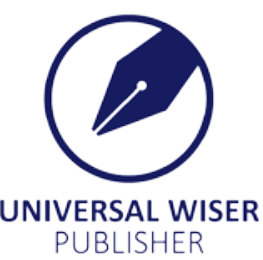

\title{
Insight into Adult Classic Theatre Audiences' Perceptions and Behaviour
}

\author{
Mirna Leko Šimić*, Ana Pap \\ Faculty of Economics in Osijek, Gajev trg 7, 31000 Osijek, Croatia \\ E-mail: lekom@efos.hr
}

\begin{abstract}
Many cultural institutions are experiencing challenges to implement different types of market-oriented behaviour in order to ensure their existence. Classic theatres are faced with many challenges related to their audience. One of the challenges is related to traditional audience that is declining and ageing. The aim of this research was to identify and analyse the key factors that contribute to understanding of attitudes and behaviour of 35+ theatre audiences in order to suggest appropriate marketing strategies for the classic theatre in Croatia. The research was conducted on altogether 438 participants. Statistical techniques of univariate analysis (frequency distribution, central tendency measures), bivariate (ANOVA and t-test) and multivariate analysis (reliability analysis, linear regression) were used. The results have identified attitudes and audience behaviour in relation to HNK Osijek. Three major factors were identified: theatre marketing profile, theatre people and stereotypes. This study seeks to provide a deeper understanding of classic theatre audiences' perceptions and behaviour as a basis for theatre marketing strategy development. Since no other research has tested the influence of stereotypes on theatre attendance, the major contribution of this paper is its proven negative influence on theatre attendance.
\end{abstract}

Key words: theatre marketing, audience, attitudes, behaviour, stereotypes

\section{Introduction}

Classic theatres worldwide are faced with numerous challenges that are related to demand-side, i.e. consumers of their product - the traditional audience is declining and aging. Moreover, according to Mandel ${ }^{[23]}$, it is becoming increasingly (too) homogeneous in terms of ethnicity, education and age. In most of the contemporary performing arts literature studies (Kotler et al. ${ }^{[21]}$, Colbert ${ }^{[7]}$ ) it is widely accepted that demand stimulation can be achieved by implementation of marketing. Kotler and Scheff ${ }^{[18]}$ promote "customer -centered organizational mindset" in cultural organizations, which is based on value creation for identified existing or potential customers. Increased competition of cultural institutions and programs is, according to Wroblewski ${ }^{[42]}$, one of the major changes, resulting in need to ensure that strategies of cultural institutions meet the changing needs of their customers.

Therefore, many cultural institutions are experiencing challenges to implement different types of market-oriented behaviour in order to ensure their existence. However, Wroblowski ${ }^{[40]}$ at the same time points out the problem of lack of both theoretical knowledge and practical experience, aversion to marketing by cultural institutions' managers and identification of marketing with sales and advertising as major barriers to marketing implementation.

Croatia has undergone the transition process to market economy that has provoked number of additional challenges in the marketing environment in culture market. Increased number of cultural institutions that are trying to attract interest, time and money of potential audience is one of the major challenges. For example, the number of professional theatres, both public and private, has increased from 14 in 1984 to 60 in 2011 and to 91 in 2016. (SYRC ${ }^{[36]}$ ). A simple mathematics on data provided by the same source shows that the number of professional theatres in period 2011 to 2016 has increased by $51 \%$, while the number of visitors has increased by $39.5 \%$. At the same time, the public (budgetary) financing of public cultural institutions in Croatia has significantly decreased (in 2011 it was $0.69 \%$ of GDP, i.e. 72 Euros per capita). In comparison to other EU countries, Croatia is in the lower mid group together with Czech Republic, Malta and United Kingdom. The highest ratio of culture in GDP was recorded in Spain (6.78\% of GDP), and the lowest in Portugal (0.30\%). (Ministry of Culture of the Republic of Croatia, ${ }^{[24]}$. On the other hand, the worsening of economic situation causes increased limitation of personal or family budget and often makes price the key element in buying decision concerning cultural products. According to Eurobarometer research ${ }^{[12]} 20 \%$ of Croatian citizens cannot afford a visit to theatre.

Copyright (C2020 Mirna Leko Šimić, et al

DOI: https://doi.org/10.37256/ges.112020146.12-22

This is an open-access article distributed under a CC BY license

(Creative Commons Attribution 4.0 International License)

https://creativecommons.org/licenses/by/4.0/ 
Moreover, there is increasingly blurred difference between so called "high" and "popular" culture. Decreasing ratio of audiences is dedicated and loyal only to "high culture" products, which is mostly represented in classic theatres. Instead, they are ready to mix and accept different forms of culture and arts.

Such a situation in culture market calls for more accountable behaviour of arts and culture institutions, need to become more independent from public financing, stimulating audience participation and for building competitive market position in relation to other players in entertainment industry (Boorsma and Chiaravalotti ${ }^{[4]}$ ). As Kolb ${ }^{[18]}$ states, these changes create numerous challenges for cultural institutions marketing

1. art can no longer be treated as having a "sacred right" to public support

2. cultural marketers can no longer assume that they know what the consumer wants from cultural experience

3. consumers living in multimedia, cross cultural environment want more combinations of art forms and new delivery methods

4. cultural marketers must target packaged events to specific market segments

5. those packaged events must provide multiple benefits to meet consumer needs, while fitting within consumers' time and budget constraints.

Scheff Bernstein ${ }^{[31]}$ also emphasizes the need for marketing approach for cultural institutions in order to efficiently face the identified challenges. Such an approach requires systematic studies of consumers' needs and wants, perceptions and attitudes, preferences and satisfaction.

The aim of this research is to analyse the attitudes and behaviour of 35+ theatre audiences in order to suggest appropriate marketing strategies for the classic theatre in Croatia. Several studies (for example Leko Šimić, Mikrut, Štimac ${ }^{[22]}$ ) on young classic theatre audience suggests that they are not presently critical for theatre survival $-49 \%$ of them have never visited classic theatre and there is only $1 \%$ of loyal theatre consumers (subscribers). It seems that $35+$ audiences is the most attractive target market and it need to be carefully studied.

The study was concentrated on Croatian National Theatre in Osijek (HNK Osijek), in Osijek-Baranja County, as one of the most important cultural institutions in Eastern Croatia. It is owned by the municipality of Osijek and Osijek Baranja County (50:50). HNK Osijek, however, is not wholly funded by the owners, but must earn revenues (around 10\%) on the market through ticket sales, space rent, sponsorships or similar.

In smaller, less developed areas like Eastern Croatia and Osijek Baranja county theatre management is rather challenging. It often depends on the ability of a theatre to create a lineup of (commercially oriented) performances that have a wider audience appeal, and thus are able to attract larger audiences (Shaomian and Heere ${ }^{[35]}$ ). At the same time, the status of national theatre house defines "quality standards" for yearly production, meaning that the majority of the program has to include performances of nationally and internationally recognized cultural values. Consequently, the ability of a national theatre to adjust program to audience preferences is rather limited. However, Kotler and Scheff ${ }^{[19]}$ point out that customer-centred approach doesn't necessarily need to be applied to piece of art itself, but to the way this product is described, communicated, priced and delivered. Taking this approach can contribute to decreasing the perceived gap between artistic and customer value, and thus make marketing more applicable.

Boorsma ${ }^{[3]}$ emphasizes the hedonistic or experiential benefits of arts consumption and social factors as the most important items that create art customer value. They are applicable to classic theatres too. Simply said, if the perceived value is high enough, a person is ready to consume the product. Hedonistic benefits refer to pleasure, emotional arousal, amusement, and imaginary and sensory stimulations $\left(\right.$ Boorsma $\left.^{[3]}\right)$. In terms of classic theatre product consumption these benefits are usually stimulating, surprising and exciting (Colbert et al. ${ }^{[8]}$ ). Social factors are equally important. According to Bourdieu ${ }^{[5]}$, the major function of culture consumption is to legitimate social differences, i.e. classic theatre attendance is a social symbol of individuals' personality and social position. Beside this, Thyne ${ }^{[36]}$ identifies the need for the social contact and interaction with peers as a social motivation for culture or arts attendance. Grisolia and Willis ${ }^{[15]}$ provide a review of the most important variables in theatre demand determination. These variables include price, quality, type of play and socio-economic characteristics - education level, gender and income.

Useem and DiMaggio ${ }^{[39]}$ researched theatre attendees and non-attenders as a whole and determined that attendees were better educated people. This confirmed the findings of Nielsen and McQueen ${ }^{[25]}$ who determined that attendees at arts events had somewhat higher amounts of leisure time and were well educated professional people. The same results were confirmed by Grisolia et al. ${ }^{[16]}$. When it comes to gender, several studies (O'Hagan ${ }^{[27]}$; Quine ${ }^{[32]}$, Chan and Goldthrope ${ }^{[6]}$ ) have showed that women are more likely to attend theatre than men.

Andreasen and Belk ${ }^{[1]}$ examined the audience for theatre and symphony products and identified two groups of attendees: "culture patrons" and "socially actives". From the analysis of their lifestyle, six significant factors that influence 
theatre attendance were identified:

1. Attitude to the theatre

2. Interest in the theatre whilst growing up

3. Citing cultural activities as a preferred form of leisure activity

4. Recent attendance (within the last year)

5. An association with a traditional general lifestyle group

6. The existence of feelings of self-confidence and a preference for being seen as a leader.

Sargeant ${ }^{[34]}$ applied cluster analysis to theatre attendees in Plymouth area of South Devon in United Kingdom and identified three segments: nouveau sophisticats (young adults with the interest in most forms of art who are less susceptible to price than other groups), blue mooners (the least well educated segment, infrequent attenders, most likely married with teenage children, not committed to a wide range of art forms) and ageing socialites (the oldest segment, predominantly over 45, with a particular interest in all types of plays and would also consider viewing other related art forms such as concerts, ballet and dance).

When analysing antecedents of theatre attendance, approaches to marketing in the performing arts (e.g. Kotler and Scheff ${ }^{[19]}$; Rentschler et al. ${ }^{[33]}$; Voss and Cova ${ }^{[40]}$ ) distinguish between the main service on one hand and the additional service(s) on the other hand. Sauter et al. (1986) as cited in Boerner et al ${ }^{[2]}$ developed an instrument covering the following elements of the main service: (1) elements referring to the fiction of the performance (story, topic of play, parts), (2) elements of the stage direction and of performing (e.g. rhythm of the performance, voice, facial expression, the ensemble as a whole, the principle performer's style of shaping the part), (3) elements of the stage design and the costumes, and (4) elements of the music (if appearing). Following this approach, Boerner et al. ${ }^{[2]}$ proposed the main service in theatre to be composed of (1) the topic of the play, (2) stage direction, (3) the ensemble, (4) the principal performer, (5) stage design, and (6) music. When it comes to additional service, same authors suggest that service quality comprises the infrastructure and the service delivered by the theatre.

Kotler and Scheff, $\left({ }^{[19]}\right.$, p. 190) cite the research conducted by Bourgeon about spectators' response to a theatre performance. Bourgeon has discovered perceptions of quality (production, acting, the play, the message), perceptions of the ambience as well as emotions to be determinants of theatregoers' satisfaction. Garbarino and Johnson ${ }^{[14]}$ in their research identified selected plays, actors, theatre facilities, and theatre locations as determinants of attenders' overall satisfaction with a theatrical event.

Pap et al. ${ }^{[28]}$ emphasize the importance of customer engagement and in their results suggest that future behaviour of theatre audience is positively influenced by perceived value of theatre performances and customer engagement.

On the other hand, Kay et al. ${ }^{[17]}$ have analysed theatre non-attendance and from the thematic content analysis of the literature identified eight broad themes that cover these barriers: (1) physical access; (2) personal access; (3) cost; (4) time and timing; (5) product; (6) personal interest; (7) understanding and socialisation; and (8) information. Their research generally supported these barriers, although it is also identified that there are complex interrelationships between the issues (for example, transportation barriers might be related to cost and time issues, as the lack of transportation means it takes more time and/or is more expensive, thus restricting visitation).

\section{Methodology}

The aim of the research was to identify major characteristics, attitudes and behaviour of 35+ population in Osijek Baranja County in relation to HNK Osijek. Research was conducted in Osijek Baranja County, an eastern Croatian county where HNK Osijek is one of the major cultural institutions. Population of $35+$ was chosen for a few reasons: previous studies have been done on young audiences, so we found interesting to compare the findings; secondly, population of $35+$ has already built its "cultural profile" and it is highly unlikely that it will be significantly changed. Therefore, they represent a realistic potential for creation of theatre marketing strategy.

A self-completion questionnaire was developed upon analysis of previous studies and distributed to $35+$ population in the County. The stratified random sampling was used.

The secondary research on sociodemographic characteristics of Osijek Baranja County shows that out of total population of 290 412, the majority of population belongs to age group of 35+, altogether 175265 inhabitants. Relatively largest population group is within the age group 50-59 (almost 50 000, i.e. $15.5 \%$ of the total). (SYRC ${ }^{[36]}$ ) The County is relatively underdeveloped, which can be illustrated by the fact the unemployment rate in March 2018 was 17,9\% while the average unemployment rate for the entire country in the same period was 11,5\% (Croatian Employment Service ${ }^{[9]}$ ). National average net income for the year 2016 was 5.049,00 KN (around 670 Euros), while the average net income for 
the same period in Osijek Baranja County was 4.134,00 KN (around 550 Euros), which is 18\% lower (Croatian National Chamber ${ }^{[10]}$ ). In comparison to Zagreb, one of the most developed counties in Croatia where average net income in the same period was 6.575,00 KN (around 875 Euros) we can see large inequalities (about 30\% difference). (The strategic office for planning and development of the Zagreb city ${ }^{[37]}$ ). We emphasize this because theatre and all other cultural products consumption belong to the higher level needs for which demand exists only in higher income levels.

The problem of decrease of loyal audience in HNK Osijek is illustrated in table 1, both in terms of number of subscribers and income from subscriptions.

Table 1. Decrease of loyal consumers in HNK Osijek

\begin{tabular}{ccccc}
\hline Theatre season & Subscribers A & Subscribers B & Subscribers seniors & $\begin{array}{c}\text { Theatre income } \\
\text { (Euro) }\end{array}$ \\
\hline $2010-2011$ & 188 & 165 & 30 & 29.700 \\
$2011-2012$ & 179 & 92 & 49 & 19.400 \\
$2012-2013$ & 152 & 95 & 66 & 21.800 \\
$2013-2014$ & 150 & 54 & 134 & 29.700 \\
$2014-2015$ & 146 & 56 & 123 & 20.500 \\
\hline
\end{tabular}

Source: HNK Osijek

In table 1, subscribers A represent subscribers for premiere theatre plays, subscribers B represent subscribers for theatre replay performances, and seniors represent special segment of subscribers who are older than 65 . Table 1 shows that the number of subscribers A and B has significantly decreased from season 2010/2011 until season 2014/2015. The only growing segment of subscribers is the senior one $(65+)$. This segment has a special low price treatment, and therefore the growth of their number is not reflected in the income growth.

\subsection{Sample description and procedure}

Altogether 438 participants took part in the research. The information obtained was analysed using the statistical software package SPSS version 21.0. Statistical techniques of univariate analysis (frequency distribution, central tendency measures), bivariate (ANOVA and t-test) and multivariate analysis (reliability analysis, linear regression) were used. The major sample characteristics are shown in Table 2.

Table 2. Sample description

\begin{tabular}{|c|c|c|c|}
\hline \multirow{2}{*}{ Gender } & Male & 206 & 47 \\
\hline & Female & 232 & 53 \\
\hline \multirow{4}{*}{ Age } & $35-44$ & 222 & 50,7 \\
\hline & $45-54$ & 135 & 30,8 \\
\hline & $55-64$ & 58 & 13,7 \\
\hline & $65-78$ & 23 & 4,8 \\
\hline \multirow{3}{*}{ Place of residence } & Osijek & 304 & 69,4 \\
\hline & Other urban area & 84 & 19,2 \\
\hline & Rural area & 50 & 11,4 \\
\hline \multirow{3}{*}{ Marital status } & Married & 261 & 59,5 \\
\hline & Living with a partner & 76 & 17,3 \\
\hline & Single & 100 & 22,8 \\
\hline \multirow{4}{*}{ Completed level of education } & Primary school & 20 & 4,6 \\
\hline & Secondary school & 196 & 44,7 \\
\hline & High school or university & 195 & 44,5 \\
\hline & Postgraduate & 27 & 6,2 \\
\hline \multirow{3}{*}{ Employment status } & Employed & 306 & 69,9 \\
\hline & Unemployed & 73 & 16,7 \\
\hline & Retired & 59 & 13,5 \\
\hline \multirow{4}{*}{ Average monthly household income } & Up to $400 €$ & 64 & 14,6 \\
\hline & $401-800 €$ & 190 & 43,4 \\
\hline & $801-1200 €$ & 121 & 27,6 \\
\hline & Over $1200 €$ & 63 & 14,4 \\
\hline \multirow{2}{*}{ Social networks active } & Yes & 262 & 59,8 \\
\hline & No & 176 & 40,2 \\
\hline
\end{tabular}

Source: Authors' work 


\section{Results}

The first part of the questionnaire was about the demographics and lifestyle of people over the age of 35 . Determining the demographic profile of theatre audiences can help in identification of their preferences related to the theatre. The analysis has shown that the most important free time activity for them is spending time with their family: $74.4 \%$ respondents spend quality time with their family on a daily basis, they watch TV $(66 \%)$, spend time with their partner (64.5\%) and friends (36.5\%), surf the Internet (64.2\%), do housework (48.2\%) and read newspapers (40.6\%). Cultural products consumption is a poorly represented activity: $34.3 \%$ of respondents go to cinema less than once a month, $47.8 \%$ of respondents never visit popular music concerts, $33.7 \%$ respondents visit theatre, exhibitions and classic music concerts less than once in a month and $33.3 \%$ never visit cultural events.

Regarding theatre attendance, only $1.4 \%$ of respondents are subscribers, i.e. loyal consumers to HNK Osijek, $5.2 \%$ visit HNK Osijek at least once in two months, which was identified as frequent attendance, $54.5 \%$ few times a year, and $38.9 \%$ of respondents have never visited HNK Osijek.

Differences in theatre attendance among male and female audiences is statistically significant, showing that female audience has a higher tendency to attend theatre $(\mathrm{F}=4.436$, sig=0.007, $\mathrm{t}=2.714)$.

Given the age structure within older population, the results of one-way ANOVA test showed there is no statistically significant difference between age groups when it comes to attending the theatre. There is, however, statistically significant difference in the level of education, showing that respondents with higher level of education have a higher tendency to attend theatre $(\mathrm{F}=12.982$, sig $=0.000)$.

As expected, when it comes to income, there are statistically significant differences between a group with lowest income (up to 400 euro/month) and those groups with higher income. ( $\mathrm{F}=8.320$, sig $=0.000)$. Differences between groups with higher income (above 400 euro/month) are not statistically significant.

Given the previous results, it is logical to assume that working status also plays a significant role in attending the theatre. Results of one-way ANOVA show that there is statistically significant difference between unemployed and retired respondents in relation to employed respondents $(\mathrm{F}=11.088$, sig $=0.000)$. The least tendency to attend theatre is expressed among retired respondents and the highest among employed respondents.

The next part of analysis was aimed at identifying barriers to theatre attendance of those respondents that rarely or never attend theatre. These reasons, ranked by importance are the following:

1. Performances/repertoire $(\mathrm{M}=4.21)$

2. Price $(\mathrm{M}=4.03)$

3. Ambient and theatre atmosphere $(\mathrm{M}=3.53)$

4. Other cultural offer in the city $(\mathrm{M}=3.51)$

5. Dislike of "different" kind of experience that HNK offers $(\mathrm{M}=3.42)$

6. Theatre "names" $(\mathrm{M}=3.37)$

7. Location of the theatre $(\mathrm{M}=3.18)$

The two most important barriers for non-goers are repertoire and price of theatre attendance. As it was mentioned earlier, due to the status of national theatre, not much can be done in terms of repertoire, but it might be useful to apply some new types of price differentiations. Other important barriers are related to cultural competition and personal preferences for other cultural products, probably belonging to the "light culture" product group. It is also clear that usual evening performances can be a logistic problem, for those living in other urban or rural areas in the County. Organization of guest performances in other places can enable those with such a problem to become more regular visitors.

On the other hand, the theatre goers group has ranked the different aspect of HNK Osijek in the following way ( $\mathrm{M}=$ mean on the scale from 1 to 5$)$ :

1. HNK location is good. $M=4.72$

2. The HNK ambiance is good. $\mathrm{M}=4.34$

3. The repertoire is in-line with interest of the audience. $M=4.34$

4. There are attractive guest performances in $\mathrm{HNK}$. M=4.34

5. Working hours are reasonable. $\mathrm{M}=4.31$

6. The staff is friendly and approachable. $M=4.21$

7. Reputation in the local community is good. $\mathrm{M}=3.97$

8. Information availability is good. $\mathrm{M}=3.90$

9. There is not enough new plays. $\mathrm{M}=3.82$

10. Prices are affordable. $M=3.72$ 
11. Theatre is for everyone. $M=3.59$

12. The best actors left from Osijek to Zagreb. $\mathrm{M}=3.59$

13. The theatre is primarily intended for intellectuals. $M=3.29$

14. You have to buy special clothes when going to HNK. $M=3.0$

15. HNK has good guest performances. $M=2.66$

16. It takes a special preparation to visit theatre. $\mathrm{M}=2.41$

17. HNK staff is good in doing their job. $\mathrm{M}=2.41$

Location, repertoire, ambience and good guest performances are characteristics of HNK Osijek that were ranked as of highest quality by theatre goers. Location is a given fact and repertoire can be adjusted only to a certain extent, as explained above. The ambience of a theatre is very specific (the building is a national heritage). Since the theatre product is actually the service, characterized by intangibility, the material aspects of the place where the service is provided represent a significant "quality signal" for the customers (Kotler and Armstrong ${ }^{[20]}$ ). Therefore, the ambience is very important as well as the reputation in the local community for the perception of HNK Osijek quality. Both of those are ranked above the average.

The next part of the analysis was aimed to compare differences between theatre goers and non-goers in the importance of some key elements of the theatre marketing profile. Those respondents who often visit HNK and its subscribers were classified as goers, while those respondents who never or rarely visit HNK were classified as non-goers. The comparison of results between the two groups is shown in Graph 1.

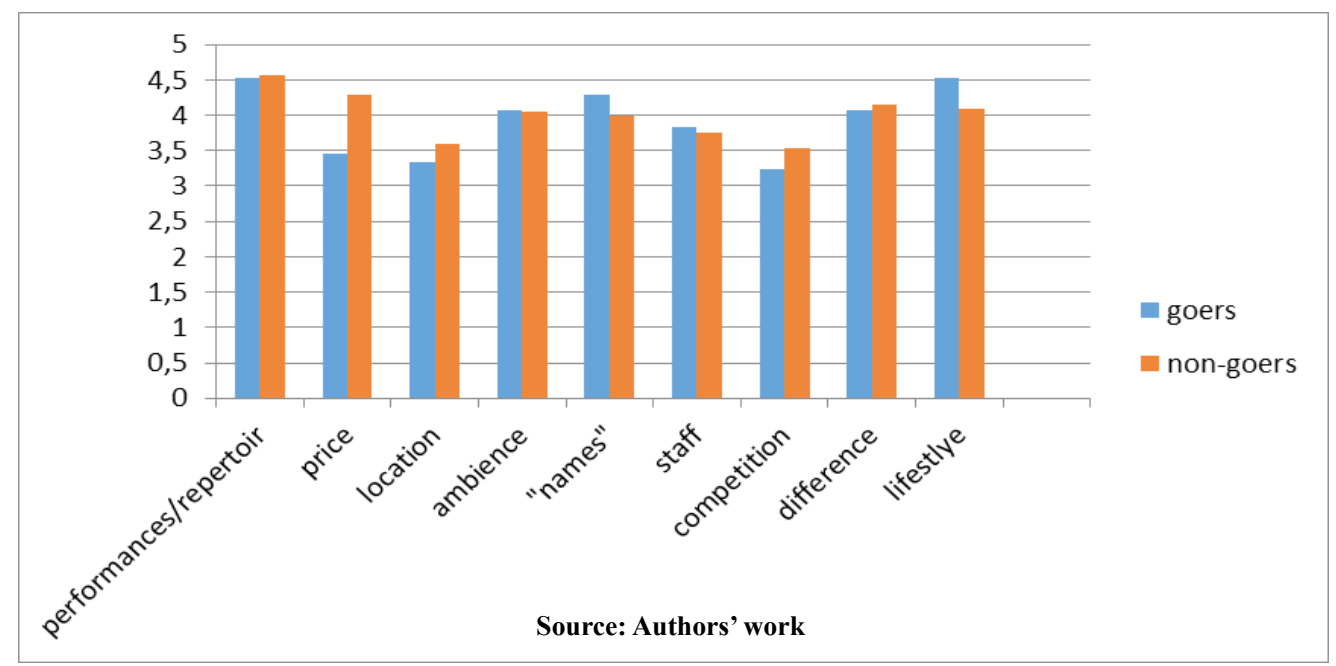

Graph 1. Importance differences between respondents who never or rarely attend theatre and subscribers and those who often attend theatre

The major similarities between the two groups are found in the highest and the lowest ranked items: for both groups performances/repertoire is the ranked as most important item, and other cultural programs offer in the area is ranked as of lowest importance. The major differences are in importance of price, where theatre goers perceive the price significantly lower barrier than non-goers. The other most important difference is found in the importance of theatre attendance as symbol of desirable lifestyle. Theatre goers value this item significantly higher than non-goers.

Further analysis was made to identify the critical areas which contribute to good value perception in the group of theatre goers. The classic comparison between expectations and perception, i.e. satisfaction defined as a measure of service quality by Parasuraman, Zeithaml and Berry ${ }^{[29]}$ was used 
Table 3. Expectations vs. satisfaction (only respondents that are subscribers and often attend theatre)

\begin{tabular}{|c|c|c|c|}
\hline & Expectations (Mean) & Satisfaction (Mean) & Difference \\
\hline Performances/repertoire & 4.52 & 3.86 & -0.66 \\
\hline Price & 3.45 & 3.68 & 0.23 \\
\hline Location of the theatre & 3.34 & 4.56 & 1.22 \\
\hline Ambience/atmosphere in the theatre & 4.07 & 4.08 & 0.01 \\
\hline Theatre names - actors, directors & 4.28 & 3.48 & -0.8 \\
\hline Staff & 3.83 & 4.11 & 0.28 \\
\hline Other cultural offer in the city & 3.24 & 3.59 & 0.35 \\
\hline HNK offers a "different" kind of experience & 4.07 & 3.63 & -0.44 \\
\hline $\begin{array}{l}\text { Attending theatre is recognized as a part of a lifestyle of those } \\
\text { who know true values }\end{array}$ & 4.52 & 3.67 & -0.85 \\
\hline
\end{tabular}

Source: Authors' work

The most important factors that contribute to good value offered by HNK Osijek to its regular and frequent audience are: price, location, theatre ambience and staff. However, these respondents are also satisfied with the HNK Osijek competition, so care should be taken that these positive aspects remain competitive in the culture market.

On the other hand, satisfaction of this group is lower than expectations in repertoire, theatre "names", HNK Osijek differentiation from the competition, and representation of a certain (prestigious) lifestyle. This is in line with findings presented in ranks given by the same group, where stereotypes of the theatre exclusivity are holding the lowest ranks.

In order to explore respondents' attitudes about HNK and theatre in general in more detail, exploratory factor analysis was conducted. Altogether 13 statements were used in which respondents evaluated their level of agreement from 1 to 5 .

Table 4. Results of exploratory factor analysis

\begin{tabular}{|c|c|c|c|}
\hline & \multicolumn{3}{|c|}{ Factor } \\
\hline & $\begin{array}{c}\text { Theatre marketing } \\
\text { profile }\end{array}$ & Theatre people & Stereotypes \\
\hline The HNK ambiance is good. & .449 & & \\
\hline The repertoire is in-line with interest of the audience. & .573 & & \\
\hline Prices are affordable. & .655 & & \\
\hline Reputation in the local environment is good. & .659 & & \\
\hline Working hours are reasonable. & .615 & & \\
\hline HNK location is good. & .466 & & \\
\hline HNK staff is good in doing their job. & & .719 & \\
\hline There are enough new plays. & & .612 & \\
\hline The best actors stayed in Osijek. & & .644 & \\
\hline The staff is friendly and approachable. & & .467 & \\
\hline You have to buy special clothes when going to HNK. & & & .818 \\
\hline It takes a special preparation to visit theatre. & & & .440 \\
\hline The theatre is primarily intended for intellectuals. & & & .451 \\
\hline
\end{tabular}

Source: Authors' work

The Principal Axis Factoring was applied. Data suitability was calculated with KMO (Kaiser-Meyer-Olkin) measure of sampling adequacy and its value is 0.915 , which is rather high, indicating that factor analysis is appropriate. Bartlett's test of sphericity is significant $(\chi 2=2289,204 ; \mathrm{df}=120$; sig. $=0.00)$, which indicates strong correlation between variables and factors, and their appropriateness for exploratory factor analysis. Items with loadings smaller than 0.4 were dropped from further analysis. Likewise, items that loaded on more than one factor were assigned to the factor where they achieved higher factor loading.

Exploratory factor analysis has extracted three factors consisting of altogether 13 variables. Factor 1 was named theatre marketing profile since it covers the product, price and location. Factor 2 was named theatre people and includes both staff and performers and Factor 3 was named stereotypes.

Although we were not able to find any research on stereotypes impact on theatre attendance, performed factor analysis has indicated that they are an important issue in attitudes toward theatre. Three major stereotypes related to the theatre attendance were analysed:

1. You have to buy special clothes for theatre.

2. It takes a special preparation to visit theatre.

3. The theatre is primarily intended for intellectuals.

Regression analysis was taken to test if stereotypes have influence on theatre attendance. Independent variable was 
comprised of three above mentioned statements. Cronbach's alpha coefficient for these statements was 0,727. According to Nunnually ${ }^{[26]}$, all coefficients above 0.7 are considered acceptable. Dependent variable was comprised of one statement where respondents evaluated the frequency of their theatre attendance.

Linear regression tests using standard regression method were subsequently conducted to find out if stereotypes have negative influence on theatre attendance. Table 5. depicts summary of a model.

Table 5. Model summary

\begin{tabular}{ccccc}
\hline Model & $\mathbf{R}$ & $\mathbf{r}^{2}$ & Adjusted $\mathbf{~ r}^{2}$ & Std. Error of the estimate \\
\hline 1 & $0.212^{\mathrm{a}}$ & 0.045 & 0.043 & 0.620 \\
\hline \multicolumn{4}{c}{ a. Predictors: (Constant), Stereotype } \\
b. Dependent Variable: Theatre attendance \\
Source: Authors' work
\end{tabular}

ANOVA results showed that the model reached statistical significance $(\mathrm{Sig}=0.000)$. Table 6 . depicts regression coefficients.

Table 6. Regression coefficients

\begin{tabular}{|c|c|c|c|c|c|c|}
\hline & \multirow{2}{*}{ Model } & \multicolumn{2}{|c|}{ Unstandardized coefficients } & \multirow{2}{*}{$\begin{array}{c}\text { Standardized coefficients } \\
\text { Beta }\end{array}$} & \multirow{2}{*}{$\mathbf{t}$} & \multirow{2}{*}{ Significance } \\
\hline & & B & Std. Error & & & \\
\hline \multirow{2}{*}{1} & (Constant) & 1.945 & 0.061 & & 31.790 & 0.000 \\
\hline & Stereotype & -0.028 & 0.006 & -0.212 & -4.440 & 0.000 \\
\hline
\end{tabular}

Source: Authors' work

The results of linear regression show that certain stereotypes about theatre have significant direct negative influence on attending the theatre $(\mathrm{t}=-4.440 ; \mathrm{p}=0.000 ; \beta=-0.212)$.

\section{Discussion}

Research results obtained in this study confirm several previous findings regarding significant differences regarding theatre attendance. Regarding gender, typical Croatian theatre attendant is female, which corresponds to the findings of O'Hagan ${ }^{[27]}$, Quine ${ }^{[32]}$ and Chan and Goldthrope ${ }^{[6]}$ ) in other countries. Higher level of education proved to be a significant determinant of theatre attendance, and the same was found in studies provided by Diniz and Machado ${ }^{[11]}$ in Brasil, in Italy by Favaro and Frateschi ${ }^{[13]}$ and in Great Britain by Grisolia et al. ${ }^{[16]}$. The same was found for classical music consumption in Spain by Prieto-Rodríguez and Fernández-Blanco ${ }^{[30]}$. Furthermore, income plays an important role in theatre attendance. As it was mentioned earlier, about $20 \%$ of Croatian citizens cannot afford a visit to theatre, and it can be relatively more significant in Eastern Croatia where the living standard is below average. Chan and Goldthorpe ${ }^{[6]}$ also found a highly significant and positive effect of income on theatre and cinema attendance. The same was confirmed by Werck, and Heyndels study ${ }^{[41]}$ in case of Flammish theatres.

Regarding differences between theatre goers and non-goers, the major differences found are in the importance of price, where theatre goers perceive the price significantly lower barrier than non-goers. The second most important difference is found in the importance of theatre attendance as a symbol of desirable lifestyle. Theatre goers value this item significantly higher than non-goers. This confirms the findings of Bourdieu ${ }^{[5]}$ and Thyne ${ }^{[38]}$ regarding the importance of social symbolism and social benefits perceived by theatre audience.

This study has identified three key factors that contribute to understanding of attitudes and behaviour of 35+ theatre audiences. Factor 1 was named theatre marketing profile since it covers the product, price and location. Factor 2 was named theatre people and includes both staff and performers and Factor 3 was named stereotypes. Since there is a research gap in studying stereotypes and its role in theatre attendance, it was emphasized in this study. Stereotypes about theatre proved to have significant direct negative influence on theatre attendance. Previous study on young theatre audience in Croatia (Leko Šimić et al., ${ }^{[22]}$ ) indicated that huge segment of young people still thinks that visiting HNK needs special preparation and is not for everybody (not related to age, but to education and social status), so they do not feel that they belong there, which is a clear indication of stereotypes.

\section{Conclusion}

Classic public theatres are facing numerous challenges in effort to retain or improve their market position. The main 
objective of this paper was to analyse behaviour and attitudes toward classic theatre of 35+ population. The adult segment was chosen due to the fact that their cultural profile is already built up and is highly unlikely that it will significantly change. Moreover, this segment represents the most likely group to consume classic theatre products, according to research on theatre demand socio-economic factors (Grisolia and Willis, ${ }^{[15]}$; Bourdieu, ${ }^{[5]}$; Thyne, ${ }^{[38]}$ ). Our results reveal that cultural products consumption is a poorly represented activity in general - one third of respondents never visits cultural events, and regarding classic theatre consumption, only $1.4 \%$ of respondents are subscribers, i.e. loyal consumers to HNK Osijek and 5.2\% visit HNK Osijek at least once in two months, while $38.9 \%$ of respondents have never visited HNK Osijek. This research has confirmed some previous research about demographic characteristics of theatre goers and nongoers. The results showed that when it comes to theatre attendance - women, highly educated people, employed people and people with higher income - are more likely to attend theatre.

There are some similarities and some differences between theatre goers (6.6\% of respondents) and non-goers (93.4\% of respondents) when analysing the importance of some elements of the theatre. The major similarities between the two groups are found in the highest and the lowest ranked items: for both groups performances/repertoire is ranked as the most important item, and other cultural programs offer (competition) in the area is ranked as of lowest importance. The major differences are in importance of price, where theatre goers perceive the price significantly lower barrier than non-goers. The other most important difference is found in the importance of theatre attendance as symbol of desirable lifestyle. Theatre goes value this item significantly higher than non-goers.

Theatre goers have evaluated price, location, theatre ambience and staff as the most important factors that contribute to good value offered by HNK Osijek. On the other hand, their satisfaction is lower than expectations when it comes to repertoire, theatre names (actors, directors), HNK Osijek differentiation from competition and representing theatre attendance as a prestigious lifestyle. Exploratory factor analysis has identified three different factors in HNK Osijek theatre attitudes. First factor was named theatre marketing profile, second factor covered theatre people, and the third factor was named stereotypes. After identifying stereotypes as an important factor in respondents' attitudes, their significant negative influence on theatre attendance was proven.

These results contribute to theatre marketing theory and practice. Theoretical models analysing theatre attendance should include stereotypes as an important factor influencing theatre audiences' behaviour and attitudes. Based on these findings, practical implications are directed to theatre marketing managers: marketing strategy should emphasize price differentiation, positioning theatre going as a desirable lifestyle and elimination of negative stereotypes in order to increase theatre attendance.

As every research, this one is not without limitations either. The first limitation is related to the sample. The sample was convenient and the highest percentage of respondents were the ones who rarely or never go to the theatre. Also, the research was limited to one country and one theatre only - HNK Osijek. Further research should include other classical theatres in Croatia. International comparisons of theatre audiences represent a significant research gap that could be addressed further on. Also, the influence of stereotypes on theatre attendance could be researched in more detail and in relation to other influential factors.

\section{References}

[1] Andreasen AR, Belk RW. Predictions of attendance at the performing arts. Journal of Consumer Research. 1980; doi: $10.1086 / 208800$

[2] Boerner S, Moser V, Jobst J. Evaluating cultural industries: investigating visitors' satisfaction in theatres. The Service Industries Journal. 2011; 31(6):877-895. doi: 10.1080/02642060902960792.

[3] Boorsma M. The strategic logic for arts marketing: Integrating customer value and artistic objectives. International Journal of Cultural Policy. 2006; 12(1): 73-92. doi: 10.1080/10286630600613333.

[4] Boorsma M, Chiaravalotti F. Arts marketing and performance management: Closing the gap between mission and indicators. In: Proceedings of the $5^{\text {th }}$ Conference on Performance Measurement and management Control, 2009; 23-25 September 2009, Nice, France.

[5] Bourdieu P. Harvard University Press; Cambridge, MA: 1984. Distinction: A Social Critique of the Judgement of Taste.

[6] Chan TW, Goldthorpe JH. The social stratification of theatre, dance and cinema attendance. Cultural Trends. 2005; 14(3):193-212. doi: 10.1080/09548960500436774.

[7] Colbert F. Marketing culture and the arts, 2007; $3^{\text {rd }}$ ed. Montreal, Canada: HEC.

[8] Colbert F, Nantel J, Bilodeau S, Rich, DJ. Marketing culture and the arts. 2001; Montreal, Canada: HEC. 
[9] Croatian Employment Service Nezaposlenost i zapošljavanje, 2018. http://www.hzz.hr/UserDocsImages/OS_Sazetak_ travanj_2018.pdf. Accessed: 25 May 2018.

[10] Croatian National Chamber of Commerce: Stanje gospodarstva Osječko-baranjske županije. 2017; https://www.hgk. hr/documents/stanje-gospodarstva-obzrujan-201759ef01f2cf62d.pdf. Accesses 28 May 2018.

[11] Diniz SC, Machado AF. Analysis of the consumption of artistic-cultural goods and services in Brazil. Journal of Cultural Economics. 2011; 35(1):1-18. doi: 10.1007/s10824-010-9129-8.

[12] Eurobarometer EB special surveys: Cultural access and participation-Croatia. 2013; www.europe.eu. Accessed: 1 June 2018.

[13] Favaro D, Frateschi C. A discrete choice model of consumption of cultural goods: the case of music. Journal of Cultural Economics. 2007; 31(3):205-234. doi: 10.1007/s10824-007-9043-x.

[14] Garbarino E, Johnson MS. Effects of consumer goals on attribute weighting, overall satisfaction, and product usage. Psychology and Marketing. 2001; 18(9):929 - 949. doi: 10.1002/mar.1036.

[15] Grisolía JM, Willis KG. A latent class model of theatre demand. Journal of Cultural Economics. 2012; 36(2):113-139 doi: 10.1007/s10824-012-9158-6.

[16] Grisolía JM, Willis, K, Wymer C, Law A. Social engagement and regional theatre: patterns of theatre attendance. Cultural Trends. 2010; 19(3):225-244. doi: 10.1080/09548963.2010.495277.

[17] Kay P, Wong E, Polonsky MJ. Marketing cultural attractions: understanding non-attendance and visitation barriers. Marketing Intelligence \& Planning. 2009; 27(6): 833-854. doi: 10.1108/02634500910988717.

[18] Kolb BM. Marketing for cultural organizations. 2005; London, UK: Thomson Cenage Learning.

[19] Kotler R, Scheff J. Standing room only. Strategies for marketing the performing arts. 1997; Boston: Harvard Business School Press.

[20] Kotler P, Armstrong G. Principles of marketing. 2001; Pearson Global Education.

[21] Kotler NG., Kotler P. Kotler WI. Museum Marketing and Strategy, 2008; $2^{\text {nd }}$ ed. San Francisco, CA., USA: JosseyBass.

[22] Leko Šimić, M., Štimac, H., Mikrut, M. Theatre marketing: young audience perceptions and behaviour. Cultural management: Science and Education. 2018; 2 (1): 31-46. DOI: 10.30819/cmse.2-1.02.

[23] Mandel B. Kulturmanagement, audience development, kulturelle Bildung. 2008; Transcript, Bielefeld, Germany.

[24] Ministry of Culture of Republic Croatia Financiranje javnih potreba u kulturi Republike Hrvatske 2011. 2012; http:// www.minkulture.hr/kulture.hr/userdocsimages/FINANCIRANJE/Dopis\%20Ministrice\%20kulture.pdf. Accessed: 1 June 2018.

[25] Nielsen R, McQueen C. Performing arts consumer behaviour: an exploratory study, in New marketing for social and economic progress. American Marketing Association Proceedings. 1975; 392-395.

[26] Nunnally J. Psychometric methods. 1978; New York: McGraw-Hill.

[27] O'Hagan J. Policy analysis of theatre in the UK. Cultural Trends. 1999; 25-29. doi: 10.1080/09548969909365077.

[28] Pap A, Dlačić J, Ham M. What makes the theatre audience return? The role of engagement in predicting future behavior. Proceedings of 4th International Scientific Conference ToSEE-Tourism in Southern and Eastern Europe 2017: "Tourism and Creative Industries: Trends and Challenges" Opatija : University of Rijeka, Faculty of tourism and hospitality management, 2017; 423-435.

[29] Parasuraman A, Zeithaml VA, Berry LL. SERVQUAL: A multiple-item scale for measuring consumer perceptions of service quality. Journal of Retailing. 1988; 64(1):12-40.

[30] Prieto-Rodríguez J. Fernández-Blanco V. Are popular and classical music listeners the same people? Journal of Cultural Economics. 2000; 24(2):47-164. doi: 10.1023/A:1007620605785.

[31] Scheff Bernstein, J. Arts Marketing Insights: The Dynamics of Building and Retaining Performing Arts Audiences. 2007; Jossey-Bass, San Francisco, CA.

[32] Quine M. Audiences for live theatre in Britain: the present situation and some implication. Cultural Trends. 1999; 9(34), 1-24.

[33] Rentschler R, Radbourne J, Carr R, Rickard J. Relationship marketing, audience retention and performing arts organization viability. International Journal of Nonprofit and Voluntary Sector Marketing. 2002; 7(2):118-130. doi: 10.1002/nvsm.173.

[34] Sargeant A. Marketing the Arts-A Classification of U. K. Theatre Audiences. Journal of Nonprofit \& Public Sector Marketing. 1997; 5(1): 45-62. doi: 10.1300/J054v05n01_04.

[35] Shaomian A, Heere B. The path to loyalty among theatre patrons: the importance of interaction and a sense of brand community. MEIEA Journal. 2015; 15(1):13-35. doi: 10.25101/15.1.

[36] SYRC. Statistical Yearbook of Republic of Croatia. 2017; 28-4). https://www.dzs.hr/Hrv_Eng/ljetopis/2017/sljh2017. pdf. Accessed 1 June 2018.

[37] The strategic office for planning and development of the Zagreb city. Communication. 2017. https://www.zagreb.hr/ 
userdocsimages/arhiva/statistika/2017/pla\%C4\%87e\%202017/Place\%20I\%202017.pdf. Accessed: 28 May 2018.

[38] Thyne M. The importance of values research for non-profit organizations: The motivation-based values of museum visitors. International Journal of Nonprofit and Voluntary Sector Marketing. 2000; 6(2):116-130. doi: 10.1002/ nvsm. 140.

[39] Useem M, DiMaggio P. A critical review of the content quality and use of audience studies of the national endowment for the arts. 1978; Baltimore: Walters Arts Gallery.

[40] Voss ZG, Cova V. How sex differences in perceptions influence customer satisfaction: A study of theatre audiences. Marketing Theory. 2006; 6(2):201-221. doi: 10.1177/1470593106063983.

[41] Werck K, Heyndels B. Programmatic choices and the demand for theatre: the case of Flemish theatres. Journal of Cultural Economics. 2007; 31(1): 25-41. doi: 10.1007/s10824-006-9026-3.

[42] Wroblewski, L. Culture Management: Strategy and marketing aspects. 2017; Berlin: Logos Verlag Berlin GmbH. 